Article

\title{
Gamma Radiation Sterilization Dose of Adult Males in Asian Tiger Mosquito Pupae
}

\author{
Andre Ricardo Machi 1,*(D), Raquel Rodrigues Mayne ${ }^{2}$, Márcio Adriani Gava ${ }^{3}$, \\ Paula Bergamin Arthur ${ }^{1}$ and Valter Arthur ${ }^{1,2}$ \\ 1 Department of Irradiation Technology Center-CTR, University of São Paulo/Institute of Nuclear Energy \\ Research-IPEN/USP, São Paulo SP 05508-000, Brazil; paula.bergamin@hotmail.com (P.B.A.); \\ arthur@cena.usp.br (V.A.) \\ 2 Department of Radiobiology and Environment-University of São Paulo/Center for Nuclear Energy in \\ Agriculture-CENA/USP, University of São Paulo, Piracicaba SP 13400-970, Brazil; \\ raquel.mayne@hotmail.com \\ 3 Análises e Estudos Biológicos-AEB-Sítio Santa Isabel, 95 km Road, Rio \\ Claro-SP-Charqueada SP 13515-000, Brazil; marciogava@asrlaboratorio.com.br \\ * Correspondence: rica_machi@hotmail.com
}

Received: 3 January 2019; Accepted: 22 March 2019; Published: 8 April 2019

Abstract: The pathogen-carrying tiger mosquito, Aedes albopictus, has spread from the Western Pacific and Southeast Asia to Europe, Africa, the Middle East, North and South America, and the Caribbean. This species of mosquito transmits arboviral infections, such as yellow fever, chikungunya, dengue, zika, and several encephalitides. The objective of this research was to provide a radiation dose inducing sterilization in adult male Ae. albopictus in the pupal stage. A cobalt-60 source of gamma radiation at a dose rate of $381 \mathrm{~Gy} / \mathrm{h}$ was used. The pupae were irradiated with doses of 0 (control), 20, 30, 40, 50, and $60 \mathrm{~Gy}$. Each treatment had a total of five replications using 60 pupae. After irradiation, the different phases of Ae. albopictus development (egg, larva, pupa, and adult) in the F1 generation were observed daily. Parameters such as viability, fertility, longevity, and mortality were recorded. The results from these studies showed that a dose of 60 Gy was necessary to sterilize $100 \%$ of the male Ae. albopictus pupae.

Keywords: Aedes albopictus; ionizing radiation; pupae; mosquitoes; sterile

\section{Introduction}

The invasive nature of the Asian tiger mosquito, Aedes albopictus, was described in Albania in 1979 [1]; subsequently, the species was introduced into the United States. Since then, several introgressions of Asian tiger mosquito across the world have been reported. Prior to 1980 [2], the species was also reported in Belgium, France, Italy, Switzerland, the Middle East, Cameroon, Equatorial Guinea, and Nigeria. In the New World, Ae. albopictus spread to Mexico by the early 1990s [3,4], and after this [5], all countries of Central America confirmed its presence in 2010.

In Italy, the Asian tiger mosquito has become the most serious pest mosquito species [6,7] as it is a potential vector of arboviruses such as yellow fever, dengue, chikungunya, zika, and other infections, such as Dirofilaria immitis, which causes heartworm parasitism. However, the introgressions suggest diverse geographic origins for this invasive mosquito species. In the New World, Costa Rica and Panamá have the same groups of population origins as in Latin America [8], whereas Hawaii, Cameroon, USA, and Italian populations belong to other groups and do not share haplotypes with the Brazil populations, indicating a separate introduction of this strain into Brazil.

Ae. albopictus was first detected in Brazil (São Paulo State) in 1986 and is currently in 24 of the 27 Brazilian Federal Units $[9,10]$. Although the species has not yet been cited as a main dengue vector in 
Brazil, studies under artificial conditions suggest that this species can be infected with and subsequently transmit the dengue virus [11]. The laboratory-based Brazilian populations of Ae. albopictus have shown high vector competence for the chikungunya virus, reinforcing the importance of the entomological and epidemiological surveillance of this mosquito species in the country. In tropical zones, Ae. albopictus has developed a photoperiodic egg diapause and freezing tolerance [12-14]. The occurrence of this species is now widespread in the USA, Central America, South America, and is currently established all over Africa [15].

Several studies were designed to develop a vaccine against these arboviruses [16,17]; however, the current means of control is the elimination of the larval phase in local areas by preventing standing water as well as chemical control. These are the most frequently used methods of vector control [18].

Consequently, the intense use of these compounds by both governmental campaigns and citizens (i.e., constant and uncontrolled household self-application) has selected resistant populations to nearly all classes of insecticides available [19]. Compounds such as organochlorines, carbamates, organophosphates, and pyrethroids have been successively administered since the 1950s to control mosquito populations [20], although no knockdown resistance (kdr) insecticide resistance mutations have been found for Ae. albopictus in Latin America [21,22].

Conventional methods do not produce satisfactory results; hence, to preserve the environment, new techniques must be applied. One such method is the sterile insect technique (SIT); this method involves the release of massive numbers of sterile males that compete with fertile wild males for mating opportunities with wild female insects [9,10]. The first release of adult mosquitoes irradiated in the pupae stage was performed in 1959-1960 in Florida to control Anopheles quadrimaculatus. However, the result was not satisfactory due to the low quality of sterilization [23,24]. In 1960-1961 in Pensacola, Florida, high doses of 110-180 Gy were applied in the pupal stage, which reduced the competitiveness of the adults, with irradiation causing the ineffectiveness of the release.

Culex quinquefasciatus irradiated at 60-120 Gy was effectively released in India and Florida between 1967 and 1974 [25]. These studies confirmed that an irradiated ion during the first hours (0-24 h) of the pupal stage can be more detrimental in this stage, in comparison to older pupae, where somatic damage was lower. When older pupae were irradiated, their competitiveness was not affected. The chemosterilizant thiotepa in water was used in a project targeted against Cx. quinquefasciatus, Ae. aegypti, and Anopheles stephensi pupae, funded by the World Health Organization (WHO) and by the United States Public Health Service (USPHS) in cooperation with the Indian Council of Medical Research (ICMR). The mass rearing facility in New Delhi produced up to one million males per day at a cost of USD $\$ 40$ per million. The sterilization induced $99 \%$ sterility [26,27].

In Mombasa, Kenya, translocation homozygote strains were introduced to replace the wild Ae. aegypti population; however, fitness studies conducted in the field and laboratory showed that the translocation strains had low fertility, rate of larval development, larval and adult survival, and low mating competitiveness; consequently, none of the translocation strains became established in the field, and they rapidly disappeared [28].

In 2011, a transgenic lineage termed RIDL (release of insects carrying a dominant lethal genetic system) in Ae. aegypti strains [29] was liberated to suppress populations in Grand Cayman, which resulted in approximately $80 \%$ suppression of the wild Ae. aegypti population in the test area when compared with the experimental control area (76-78\%). In Brazil, the release of transgenic insects reduced the Ae. aegypti population density by $85 \%$ in areas located in the Juazeiro and Jacobina municipalities (Bahia State) [30].

In Italy, from 2004 until currently, research has been conducted to investigate the feasibility of introducing the SIT strategy to control Ae. albopictus. In the first experiment, adults of male pupae showed significant results for a high sterilization rate in comparison with control treatments; research is continuing on a large scale to improve rearing efficiency [31,32].

The incompatible insect technique (IIT) uses the cytoplasmic incompatibility characteristics of Wolbachia to suppress a population. Although population replacement approaches can be performed 
with the simultaneous release of both male and female insects, population-suppression strategies should aim to release only males. Besides Ae. aegypti, other mosquito species, such as Ae. polynesiensis (South Pacific), Ae. albopictus (Italy), and Culex pipiens quinquefasciatus (Southwestern Indian Ocean), are also being tested in different countries to demonstrate the feasibility of using IIT for the population control of mosquito species [32].

The use of Wolbachia to reduce dengue transmission is being tested in several countries [33]. Wolbachia-infected mosquitoes are released in large numbers weekly, and the bacteria are transmitted to the wild Ae. aegypti population. Field trials have been conducted at four sites in Australia, one in Vietnam, and two in Indonesia; experiments in Brazil have been underway since September 2014 using Ae. aegypti infected with the wMel Wolbachia strain. Laboratory and field assays performed in Brazil showed that wMel infection has no detrimental effects on the Brazilian Ae. aegypti mosquito population. This technology can be used to control mosquito populations where local access is impossible (e.g., urban areas) [34-36]. Large-scale liberation has been conducted in Brazil (Niteroi and Rio de Janeiro), Colombia (Bello and Medellin), and Indonesia (Yogyakarta).

In Brazil, the SIT technique has been applied only to Ae. aegypti pupae since 2015 [37,38]. These previous studies showed that few mosquito sterilization programs in Brazil have been reported in the literature, and none have focused on Ae. albopictus. [23]. Thus, the success of SIT in vector control programs involves an area-wide approach combined with the release of large numbers of competitive sterile males in urban and rural areas with the highest risk of arbovirus transmission and highly diverse human populations [10-12]. Despite important advances in the development of molecular mechanisms for inducing male sterility [13], sterilization by irradiation remains the most practical method to sterilize mosquitoes in terms of cost and efficiency. Thus, the implementation of intensive control programs for Ae. albopictus, which is also a potential vector of human diseases, is necessary. This species is particularly suitable for the application of the sterile insect technique (SIT) due to its urban-related distribution, recent introduction, vector potential, low population density, which can be maintained by conventional control measures, and ease of mass rearing.

Therefore, Ae. albopictus is a potential candidate for SIT application. The objective of this research was to induce a sterilizing radiation dose for adult male Ae. albopictus irradiated in the pupal stage.

\section{Materials and Methods}

The research was performed in the Laboratory of Environment and Radiobiology, Center of Nuclear Energy in Agriculture (CENA/USP), at the Universidade de São Paulo, Piracicaba-São Paulo State, Brazil and Análise e Estudos Biológicos (AEB), Charqueda-São Paulo State, Brazil. The mosquitoes used in this experiment were obtained from the mass rearing colony at the Entomology Laboratory at LAFICAVE-IBEX-FIOCRUZ (Oswaldo Cruz Foundation), Benfica, RJ and had been maintained in the laboratory for more than three years.

\subsection{Mosquito Source: Rearing and Preparation}

Insects were reared under standard laboratory conditions $\left(25^{\circ} \mathrm{C}, 75 \%\right.$ relative humidity $(\mathrm{RH})$, $12 \mathrm{~h}$ photoperiod). Adults were kept in Plexiglas cages $(50 \times 50 \times 50 \mathrm{~cm})$. The cages were supplied with deionized water and $10 \%$ honey solution and contained adult males and females aged 5 days. During this period, the mosquitoes were fed with sheep blood via a vacuum collector. Females laid eggs in Petri dishes containing deionized water and a strip of white filter paper. After oviposition, the filter paper was removed from the cage and left to dry in a closed plastic container.

After four days, the eggs were counted and placed in a $1.0 \mathrm{~L}$ closed bottle with $750 \mathrm{~mL}$ of deionized water and $0.05 \mathrm{mg}$ of food to stimulate hatching. Larvae were reared in white plastic trays $(31 \times 22 \times$ $10 \mathrm{~cm}$ ) at a density of 200 larvae/tray containing $2.5 \mathrm{~L}$ deionized water and provided with TetraMin fish food (0.20 mg; Tetra Werke, Melle, OS, Germany).

To separate males from females in the pupal stage, a device comprising two overlapping acrylic plates with an adjustable, downward-pointing, and wedge-shaped space was used, into which the 
pupae could be inserted. Pupae were separated on the basis of size by regulating the thickness and angle of the wedge-shaped space using four control knobs, one for each angle. The lower opening was adjusted so that the larger female pupae were retained in a layer in the tapering space between the acrylic plates. The smaller male pupae were drained into a plastic tray placed below. The operation was completed by opening the wedge and flushing the female pupae into a second receptacle (Model 5412, John W. Hock Company, Gainesville, FL, USA).

\subsection{Irradiation Procedure}

Each male pupa was transferred separately to a Petri dish containing white filter paper with a 10-mm layer of deionized water to sustain them. Afterward, they were placed in a Gammacell-220 irradiator (Atomic Energy of Canada, Ottawa, ON, Canada) located in then Center for Nuclear Energy in Agriculture-CENA/USP and exposed to cobalt-60 as a gamma radiation source at a dose rate of $381 \mathrm{~Gy} / \mathrm{h}$.

Doses in the irradiator were mapped by six Gammachrome dosimeters (Harwell Dosimeters, OX, UK) with a range of 0.1 to $3 \mathrm{kGy}$ and read using a Genesy 20 spectrophotometer (Thermo Fisher Scientific, Waltham, MA, USA). Doses were certified by the Institute for Energy and Nuclear Research (IPEN), São Paulo, Brazil. The traceability of dose measurements was maintained by comparison with the international service assurance dose offered by the International Atomic Energy Agency, Vienna, Austria.

The Petri dishes were centered in the irradiator to ensure the uniformity of the radiation was not disrupted. The six dosimeters were positioned as follows: one on top of the dish, one at the bottom, and four equally spaced at lateral positions. The uncertainty in each dish was $\pm 1.6 \%$. The variation in measured doses was $\pm 1.5 \%$ in the Gammacell-220 source.

Male pupae were irradiated at doses of 0 (control), 20, 30, 40, 50, and 60 Gy, with a total of five replications with 60 pupae per treatment.

After irradiation, the Petri dishes containing the adult males were transferred to new cages with 60 virgin females. The different phases of Ae. albopictus (egg, larva, pupa, and adult) in the F1 generation were evaluated daily for viability, fertility, longevity, cycle life duration of immature stages (duration stage), and mortality.

\subsection{Statistical Analysis}

A completely randomized experimental design was used in each experiment with five replications per treatment. Data were initially submitted to the Shapiro-Wilk normality test at a $5 \%$ level of significance. Proportional data were analyzed using a generalized linear model with binomial distribution. The graphics were produced with Microsoft Excel 2013 (Microsoft ${ }^{\circledR}$, Redmond, WA, USA) and R software [39].

The data with multiple comparisons regarding the number of mosquitoes on average in the larva, pupa, or adult stage when submitted to the different doses of gamma radiation were compared using the glht function of the multicomp package in $\mathrm{R}$. The survival rate of adult males from irradiated pupae and their longevity under various experimental conditions were used for Kaplan-Meier survival analysis.

\section{Results}

\subsection{Radiation Effects in the F1 Generation from Irradiated Male Pupae}

In the irradiation studies, the levels of damage were proportional to the increase in radiation doses compared with controls. This phenomenon was observed primarily in older pupae subjected to doses of $50 \mathrm{~Gy}$. The dose of $60 \mathrm{~Gy}$ was administered to all ages, and the results were compared with other doses and the controls. Doses above 30 Gy caused deformations to appear in the larval body (personal 
observations). Higher doses of 40 or $50 \mathrm{~Gy}$ resulted in lower larvae and pupae numbers, whereas in doses of $60 \mathrm{~Gy}$, no larval survival was observed. Thus, $60 \mathrm{~Gy}$ was the effective sterilizing dose.

The results for the cycle life in each stage (egg, larva, and pupa) in days showed that some irradiation treatments were overall slightly lower than in controls. However, at dose levels of $50 \mathrm{~Gy}$, eggs developed to the larval L1-stage (L1). At doses of 40 and $50 \mathrm{~Gy}$, however, the cycle duration time increased when there was an increase in age and dose, although no statistical difference was observed in comparison with the controls.

To rate the percentage of L1-L4 larvae that transformed in the pupal stage, gamma radiation effects were measured. Gamma radiation caused a significant reduction in pupae transformation: less than $60 \%$ transformed in the $20 \mathrm{~Gy}$ dose compared with $80 \%$ in the control. This difference was shown to be statistically significant $(p<0.001)$. At the $50 \mathrm{~Gy}$ dose, approximately $3 \%$ transformation was observed compared with the 60 Gy dose, where there was no observed L1-L4 larvae stage (Table 1 and Figure 1).

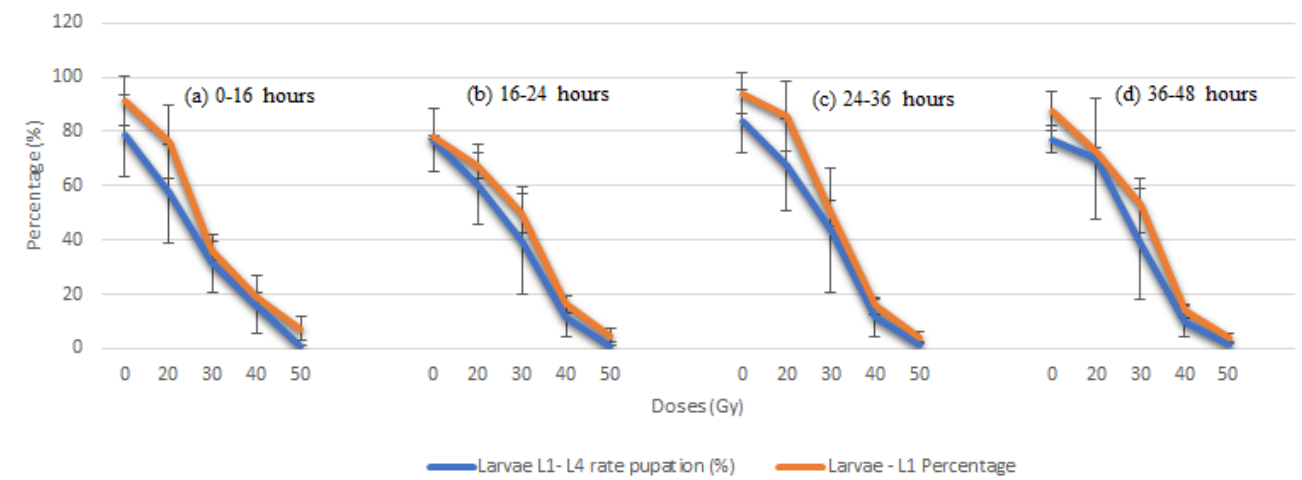

Figure 1. Percentage $( \pm S D)$ of pupation of L1-L4 larvae from adults irradiated in the pupal phase at different ages: (a) 0-16 h, (b) 16-24 h, (c) 24-36 h, and (d) 36-48 h.

Table 1. Total numbers of eggs, larvae and pupae, mean duration eggs, larvae and pupae stage, and larvae L1-L4 rates after pupae irradiation at different ages of Ae. albopictus.

\begin{tabular}{|c|c|c|c|c|c|c|c|c|}
\hline${ }^{\text {a }}$ Age (h) & $\begin{array}{c}\text { Dose Level } \\
\text { (Gy) }\end{array}$ & $\begin{array}{c}\text { Total No. } \\
\text { Eggs }\end{array}$ & $\begin{array}{l}\text { Duration of } \\
\text { Egg Stage } \\
\text { (days) }\end{array}$ & $\begin{array}{l}\text { No. Total } \\
\text { Larvae L1 }\end{array}$ & $\begin{array}{c}\text { Duration } \\
\text { Larvae L1-L4 } \\
\text { Stage }\end{array}$ & $\begin{array}{l}\text { No. Total } \\
\text { Pupae }\end{array}$ & $\begin{array}{c}\text { Duration of } \\
\text { Pupa Stage } \\
\text { (days) }\end{array}$ & $\begin{array}{c}\text { Larvae L1-L4 Rate } \\
\text { (\%) Transformed in } \\
\text { Pupae }\end{array}$ \\
\hline \multirow{4}{*}{$0-16$} & 0 & 2975 & $3.1 \pm 1.5$ & 2712 & $5.8 \pm 2.1$ & 2493 & $3.1 \pm 2.3$ & $78.4 \pm 6.7$ \\
\hline & 30 & 2.403 & $2.7 \pm 1.5$ & 2403 & $5.6 \pm 2.1$ & 872 & 312 & $2.9 \pm 2.1$ \\
\hline & 40 & 1.599 & $2.9 \pm 1.4$ & 1599 & $5.8 \pm 2.3$ & 302 & 49 & $3.2 \pm 1.9$ \\
\hline & 50 & 1.106 & $3.3 \pm 1.3$ & 1106 & $5.9 \pm 2.1$ & 182 & 14 & $3.2 \pm 1.5$ \\
\hline \multirow{5}{*}{$16-24$} & 20 & 3857 & $3.2 \pm 2.2$ & 2594 & $6.5 \pm 3.5$ & 1101 & $2.7 \pm 2.3$ & $60.4 \pm 6.1$ \\
\hline & 30 & 3203 & $2.9 \pm 2.4$ & 1603 & $6.2 \pm 3.2$ & 203 & $2.7 \pm 2.0$ & $39.8 \pm 4.1^{*}$ \\
\hline & 40 & 2498 & $3.6 \pm 2.8$ & 409 & $8.3 \pm 3.3$ & 34 & $3.1 \pm 1.9$ & $11.8 \pm 2.3 *$ \\
\hline & 50 & 2099 & $3.5 \pm 2.6$ & 100 & $8.6 \pm 3.2$ & 19 & $3.3 \pm 2.0$ & $1.1 \pm 0.1 *$ \\
\hline & 60 & 1902 & $0.0 \pm 0.0$ & 0 & $0.0 \pm 0.0$ & 0 & $0.0 \pm 0.0$ & $0.0 \pm 0.0$ \\
\hline \multirow{2}{*}{$24-36$} & 0 & 4497 & $3.3 \pm 3.1$ & 4229 & $7.6 \pm 3.8$ & 3697 & $2.9 \pm 3.4$ & $83.7+7.3$ \\
\hline & 60 & 2101 & $0.0 \pm 0.0$ & 0 & $0.0 \pm 0.0$ & 0 & $0.0 \pm 0.0$ & $0.0 \pm 0.0$ \\
\hline \multirow{6}{*}{$36-48$} & 0 & 4336 & $3.3 \pm 3.2$ & 3789 & $7.7 \pm 3.8$ & 3687 & $2.9 \pm 3.3$ & $77.1 \pm 6.4$ \\
\hline & 20 & 5125 & $3.2 \pm 3.2$ & 3699 & $6.5 \pm 4.1$ & 1201 & $2.8 \pm 3.0$ & $69.9 \pm 6.0$ \\
\hline & 30 & 3011 & $3.1 \pm 3.0$ & 1590 & $6.4 \pm 3.9$ & 72 & $2.8 \pm 2.3$ & $38.7 \pm 3.9 *$ \\
\hline & 40 & 2901 & $3.4 \pm 3.2$ & 399 & $9.1 \pm 3.4$ & 15 & $3.3 \pm 1.2$ & $9.9 \pm 2.5^{*}$ \\
\hline & 50 & 2108 & $3.6 \pm 2.9$ & 82 & $9.3 \pm 2.9$ & 16 & $3.4 \pm 1.6$ & $1.6 \pm 0.1$ * \\
\hline & 60 & 1998 & $0.0 \pm 0.0$ & 0 & $0.0 \pm 0.0$ & 0 & $0.0 \pm 0.0$ & $0.0 \pm 0.0$ \\
\hline
\end{tabular}

${ }^{*}$ Mean $( \pm \mathrm{SD})$ in rows and columns were statistically significant $(p>0.001) .{ }^{\mathrm{a}} \mathrm{h}$-(hours). ${ }^{\mathrm{b}}$ Duration stage-duration life cycle history of each immature phase of Aedes albopictus in days. 
Figure $1 \mathrm{a}-\mathrm{d}$ shows that almost $90 \%$ of the L1 larvae in the control dose transformed into pupae, whereas for the irradiated doses, $70 \%$ reached the pupal stage. However, we observed a gradual decrease in the survival of L1 larvae when there was an increase in dose that resulted in low pupa production (pupation), especially in doses from 30 Gy onward.

From doses at $50 \mathrm{~Gy}$, no larvae were observed in stage L1 and the effects of gamma radiation on irradiated treatments from doses of 20 Gy onward were harmful, being statistically significant compared with the control treatment.

\subsection{Gamma Radiation Effects on Longevity in the F1 Generation from Male Pupae}

The radiation effects on pupal age were proportional to the increase in the doses that affected adult male viability. Younger pupae were less susceptible to radiation, while older pupae showed a decreased survival ability in all treatments.

In the first seven days, there was no observed decrease in the lifespan of pupae in any treatment group studied (Figure 2a-d). A slight decrease in longevity was observed at doses of 20 and $30 \mathrm{~Gy}$ compared with controls. However, the difference was not statistically significant. At the higher dose of $40 \mathrm{~Gy}$, differences were statistically significant $(p>0.001)$. At the $60 \mathrm{~Gy}$ dose, the data obtained for male adult survival and male adult longevity were obtained from the P generation and compared with the other doses in the F1 generation. This was conducted because there were no pupae or adults in the F1 generation for this dose.

When comparing the viable percentage of adult males in Table 2, we observed a decrease proportional to the increased doses in all ages of irradiated treatments compared with the controls. We observed that the longevity of the males increased with the age of the pupae at the time of irradiation. From the initial doses of irradiation, a decreased percentage of viability was observed. At the dose of 20 Gy, viability was approximately $51 \%$ compared with $77 \%$ observed in the controls. At the 30 Gy dose, the percentage was significantly lower than $30 \%$ in all ages $(p>0.001)$. At $0-48 \mathrm{~h}$ at the 40,50 , and 60 Gy doses, the longevity of adult males in the P and F1 generations showed a significant reduction compared with the controls $(p>0.001)$.

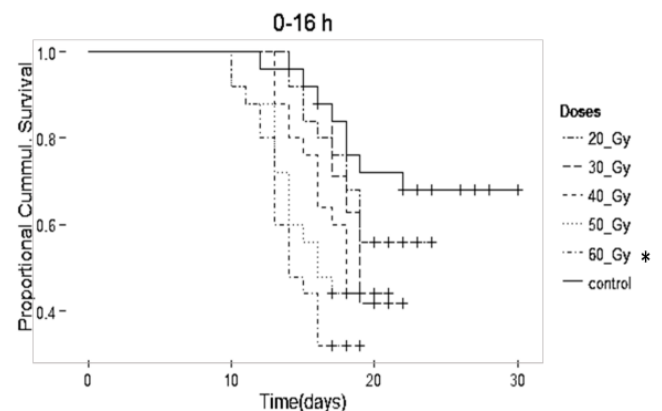

(a)

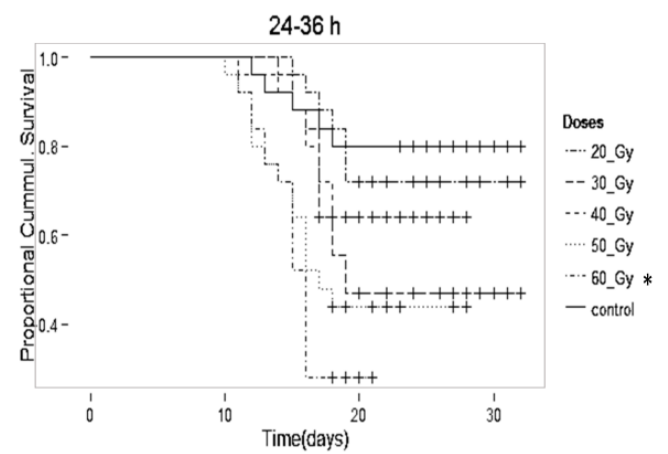

(c)

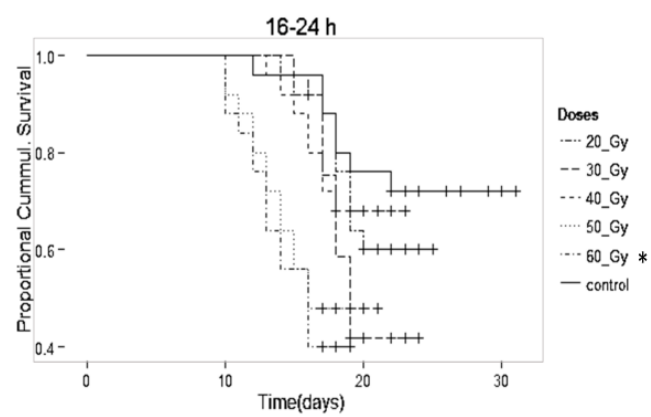

(b)

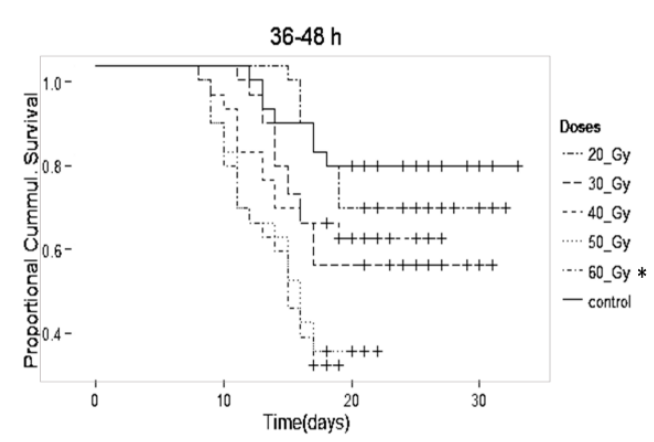

(d)

Figure 2. Adult male survival for pupae irradiated at different ages (a) 0-16, (b) 16-24, (c) 24-36, (d) 36-48 h. * Adult male at a dose of 60 Gy in $(\mathrm{P})$ generation. 
Table 2. Mean longevity of adult males and viable percentage of transformed pupae in adult males from irradiated pupae at various ages.

\begin{tabular}{|c|c|c|}
\hline $0-16 \mathrm{~h}$ & Adult Male (\%) & Male Mean Survival (days) \\
\hline Control & $75.9 \pm 3.5$ & $22.4 \pm 2.9$ \\
\hline 20 Gy & $48.1 \pm 2.9 *$ & $19.0 \pm 2.1$ \\
\hline $30 \mathrm{~Gy}$ & $12.2 \pm 1.8 *$ & $18.9 \pm 2.2$ \\
\hline $40 \mathrm{~Gy}$ & $2.0 \pm 1.0 *$ & $17.4 \pm 2.0^{*}$ \\
\hline $50 \mathrm{~Gy}$ & $0.3 \pm 0.3 *$ & $15.6 \pm 1.9 *$ \\
\hline a $60 \mathrm{~Gy}$ & $0.0 \pm 0.0$ * & $14.7 \pm 1.7^{*}$ \\
\hline $16-24 \mathrm{~h}$ & Adult Male (\%) & Male Mean Survival (days) \\
\hline Control & $76.0 \pm 3.7$ & $23.2 \pm 3.2$ \\
\hline 20 Gy & $50.8 \pm 3.0 *$ & $20.2 \pm 2.4$ \\
\hline $30 \mathrm{~Gy}$ & $22.0 \pm 2.3 *$ & $19.2 \pm 2.3$ \\
\hline $40 \mathrm{~Gy}$ & $0.9 \pm 1.1^{*}$ & $18.8 \pm 2.3^{*}$ \\
\hline 50 Gy & $0.3 \pm 0.2 *$ & $15.9 \pm 2.1 *$ \\
\hline a $60 \mathrm{~Gy}$ & $0.0 \pm 0.0$ * & $15.0 \pm 2.0 *$ \\
\hline $24-36 \mathrm{~h}$ & Adult Male (\%) & Male Mean Survival (days) \\
\hline Control & $75.8 \pm 3.2$ & $24.5 \pm 3.3$ \\
\hline 20 Gy & $48.1 \pm 2.7^{*}$ & $23.7 \pm 3.2$ \\
\hline $30 \mathrm{~Gy}$ & $17.9 \pm 2.0 *$ & $21.3 \pm 3.1$ \\
\hline $40 \mathrm{~Gy}$ & $0.5 \pm 0.4^{*}$ & $20.3 \pm 3.1 *$ \\
\hline $50 \mathrm{~Gy}$ & $0.2 \pm 0.1$ * & $17.4 \pm 2.4$ * \\
\hline a 60 Gy & $0.0 \pm 0.0 *$ & $15.6 \pm 2.1^{*}$ \\
\hline $36-48 \mathrm{~h}$ & Adult Male (\%) & Male Mean Survival (days) \\
\hline Control & $74.8 \pm 3.0$ & $22.84 \pm 3.1$ \\
\hline 20 Gy & $41.0 \pm 2.3^{*}$ & $22.68 \pm 3.1$ \\
\hline $30 \mathrm{~Gy}$ & $9.9 \pm 1.6^{*}$ & $19.5 \pm 3.0$ \\
\hline 40 Gy & $0.3 \pm 0.2$ * & $17.8 \pm 2.7^{*}$ \\
\hline $50 \mathrm{~Gy}$ & $0.2 \pm 0.1^{*}$ & $14.1 \pm 2.1 *$ \\
\hline a $60 \mathrm{~Gy}$ & $0.0 \pm 0.0$ * & $13.4 \pm 1.8$ * \\
\hline
\end{tabular}

${ }^{*}$ Means $( \pm \mathrm{SD})$ in rows and columns were statistically significant the level of $p>0.001 .{ }^{\text {a }}$ Adult male in the dose of $60 \mathrm{~Gy}$ is as the $(\mathrm{P})$ generation.

\section{Discussion}

Overall, the radiation dose required to produce sterility was proportional to an increase in the dose, as expected. Some authors reported that increasing the radiation doses in pupae in mosquito species from the genus Aedes causes a large reduction in the number of male adults [40-45]. Our study supports those conclusions.

Here, we showed that sterility was reached at the 60 Gy dose for all pupae ages $(0-48 \mathrm{~h})$. Other authors used larger doses than those reported in the present study [23,41]. For example, irradiating Ae. aegypti male pupae aged $>24 \mathrm{~h}$ resulted in a $99.9 \%$ sterility rate with a dose of 78 Gy [46]. In another study, exposing one-day-old male pupae produced a 100\% sterility rate using $70 \mathrm{~Gy}$ [41]. The results of this study showed that irradiation reduced male survival, with a rate of approximately $99 \%$ of adults eradicated at a dose of $40 \mathrm{~Gy}$. However, to reach a $100 \%$ sterilization rate, it was necessary to use a 50 Gy dose. Our results are similar to a study in Italy that induced sterilization in Ae. albopictus pupae with a 40 Gy dose; however, a 60 Gy dose was needed to achieve a $100 \%$ sterilization rate [42].

The adult emergence rate is considered to be an important parameter for measuring pupal irradiation. The radiation effects on insect pupae are greater than on adults, with the latter generally leading to a sterile male competing almost equally with wild males [47-51]. However, irradiation at the pupal stage is more convenient for practical reasons because the handling of pupae is easier than handling the more fragile adult mosquitoes. 
A significant reduction in male adult longevity was observed in radiation treatments, especially at doses of $40 \mathrm{~Gy}$ or higher. A slight reduction was also observed in other treatments when compared with controls, although there was no significant difference among the doses.

Other studies also reported a significantly negative effect on male adult longevity after the pupal irradiation of Ae. albopictus at $40 \mathrm{~Gy}$ or higher $[41,50]$. This was likewise observed in other species, such as Anopheles pharoensis and Anopheles stephensi irradiated at more than $100 \mathrm{~Gy}[48,52]$.

The possible causes of somatic injuries induced by radiation treatment that result in decreased longevity have been previously described [51-53]. This negative effect of radiation treatment appeared to be stronger during the last days of the males' lives. In the present study, it was approximately two weeks before such effects were observed. However, the results varied in some reports [49]. In these studies, An. pharoensis pupae (males and females) irradiated with low doses in the range of 4.8 to 68 Gy exhibited no reduction in longevity compared with controls (no irradiation).

Other studies on Anopheles arabiensis found that low doses, such as 4-15 Gy, could prolong the longevity of adult males [49]. The phenomenon of hormesis is proposed to explain the protective effect of a low radiation dose, which could stimulate defenses involved in cell repair mechanisms [53]. However, this was not the case in the current study.

The SIT methodology has not been attempted in Brazil, although studies of this nature have been conducted on several other mosquito species, including Ae. aegypti, which is a closely related species and may be taken as a useful example. Thus, the dose determined in this manuscript was used for the first time for the Brazilian strain of Ae. albopictus. Although positive, the results reported here need to be confirmed through a larger trial and with wild mosquitoes in the field, because laboratory strains of many generations could produce limited results in future pilot trials.

In future investigations, the main aims should be to evaluate the following: (1) the number of sterile males to be released, (2) a comparison of costs and benefits with conventional methods, (3) methods of improving the rearing efficiency by increasing larval density through introducing new larval diets and decreasing larvae numbers in plastic trays, (4) processes to increase pupal production by sieving at 30-36 h after the start of pupation instead of at $24 \mathrm{~h}$, (5) the development of a larger greenhouse for colony maintenance, (6) testing for a lower sterilizing dose, (7) a pilot trial of population suppression and operational implementation in the field, (8) improvements in the quality of sterile males, and (9) the mass rearing of wild mosquitoes to study.

\section{Conclusions}

The results presented here are important for mosquito species control programs that include SIT technology for efficient integrated pest management (IPM) in Brazil. From the results of longevity and gamma radiation doses, an effective sterilization dose was determined for male pupae of Ae. albopictus at 60 Gy.

Author Contributions: Conceptualization, A.R.M. and V.A.; Data curation, M.A.G., P.B.A. and V.A.; Formal analysis, A.R.M., M.A.G., P.B.A. and V.A.; Funding acquisition, M.A.G. and V.A.; Investigation, A.R.M., R.R.M., M.A.G. and V.A.; Methodology, A.R.M., R.R.M., M.A.G., P.B.A. and V.A.; Project administration, M.A.G. and V.A.; Supervision, M.A.G. and V.A.; Validation, R.R.M., M.A.G. and V.A.; Writing-original draft, A.R.M., M.A.G., P.B.A. and V.A.; Writing-review \& editing, A.R.M., M.A.G. and V.A.

Funding: The research no received external funding.

Acknowledgments: We would like to thank the authors, interns, and University of São Paulo for their support.

Conflicts of Interest: The authors declare no conflict of interest.

\section{References}

1. Adhami, B.J.; Murati, N. Présence du moustique Aedes albopictus en Albanie. Bul. Univ. Shtet. Tiranes Ser. Shk. Mjek. 1987, 1, 13-16.

2. Sprenger, D.; Wuithiranyagool, T. The discovery and distribution of Aedes albopictus in Harris County, Texas. J. Am. Mosq. Control 1986, 2, 217-218. 
3. Rai, K.S. Aedes albopictus in the Americas. Ann. Rev. Entomol. 1991, 36, 459-484. [CrossRef]

4. Lounibos, L.P. Invasions by insect vectors of human disease. Ann. Rev. Entomol. 2002, 47, 233-266. [CrossRef] [PubMed]

5. Eritja, R.; Escosa, R.; Lucientes, J.; Marquès, E.; Roiz, D.; Ruiz, S. Worldwide invasion of vector mosquitoes: Present European distribution and challenges for Spain. Biol. Invasions 2005, 7, 87-97. [CrossRef]

6. Romi, R. Aedes albopictus in Italy: An underestimated health problem. Annali dell'Istituto Superiore di Sanità 2001, 37, 241-247.

7. Gratz, N.G. Critical review of the vector status of Aedes albopictus. Med. Vet. Entomol. 2004, 18, $215-227$. [CrossRef] [PubMed]

8. Futami, K.; Valderrama, A.; Baldi, M.; Minakawa, N.; Rodríguez, R.M.; Chaves, L.F. New and common haplotypes shape genetic diversity in Asian tigermosquito populations from Costa Rica and Panamá. J. Econ. Entomol. 2015, 108, 761-768. [CrossRef] [PubMed]

9. Consoli, R.A.G.B.; Oliveira, R.L. Principais Mosquitos de Importância Sanitária no Brasil; Editora FIOCRUZ: Rio de Janeiro, Brazil, 1994; 228p.

10. Carvalho, R.; Lourenço-de-Oliveira, R.; Braga, I. Updating the geographical distribution and frequency of Aedes albopictus in Brazil with remarks regarding its range in the Americas. Mem. Inst. Oswaldo Cruz 2014, 109, 787-796. [CrossRef] [PubMed]

11. Forattini, O.P. Identificação de Aedes (Stegomyia) albopictus (Skuse) no Brasil. Rev. Saude Publica 1986, 20, 244-245. [CrossRef] [PubMed]

12. Vega-Rúa, A.; Zouache, K.; Girod, R.; Failloux, A.B.; Lourenço-de-Oliveira, R. High vector competence of Aedes aegypti and Aedes albopictus from ten American countries as a crucial factor of the spread of Chikungunya. J. Virol. 2014, 886, 294-6306. [CrossRef]

13. Castro, M.G.; Nogueira, R.M.R.; Schatzmayr, H.G.; Miagostovich, M.P.; Lourenço-de-Oliveira, R. Dengue virus detection by using reverse transcription-polymerase chain reaction in saliva and progeny of experimentally infected Aedes albopictus from Brazil. Mem. Inst. Oswaldo Cruz 2004, 99, 809-814. [CrossRef]

14. Hawley, W.A.; Reiter, P.; Copeland, R.S.; Pumpuni, C.B.; Craig, G.B., Jr. Aedes albopictus in North America: Probable introduction in used tires from northern Asia. Science 1987, 236, 1114-1116. [CrossRef] [PubMed]

15. Bonizzoni, M.; Gasperi, G.; Chen, X.; James, A.A. The invasive mosquito species Aedes albopictus: Current knowledge and future perspectives. Trends Parasitol. 2013, 29, 460-468. [CrossRef] [PubMed]

16. Lu, H.; Xu, X.F.; Gao, N.; Fan, D.Y.; An, J.; Wang, J. Preliminary evaluation of DNA vaccine candidates encoding dengue-2 prM/E and NS1: Their immunity and protective efficacy in mice. Mol. Immunol. 2013, 54, 109-114. [CrossRef] [PubMed]

17. Sun, W.; Eckels, K.; Putnak, J.; Lyons, A.; Thomas, S.; Vaughn, D. Experimental dengue virus challenge of human subjects previously vaccinated with live attenuated tetravalent dengue vaccines. J. Infect. Dis. Immun. 2013, 207, 700-708. [CrossRef]

18. World Health Organization (WHO). Sustaining the Drive to Overcome the Global Impact of Neglected Tropical Diseases: Second WHO Report on Neglected Tropical Diseases; World Health Organization: Geneva, Switzerland, 2013.

19. Vontas, J.; Kioulos, E.; Pavlidi, N.; della Torre Morou, E.; Ranson, A.H. Insecticide resistance in the major dengue vectors Aedes albopictus and Aedes aegypti. Pestic. Biochem. Physiol. 2012, 104, 126-131. [CrossRef]

20. Baldacchino, F.; Caputo, B.; Chandre, F.; Della Torre, A.; Drago Montarsi, F. Control methods against invasive Aedes mosquitoes in Europe: A review. Pest. Manag. Sci. 2015, 71, 1471-1485. [CrossRef] [PubMed]

21. Chaves, L.F.; Kawashima, E.; Futami, K.; Minakawa, N.; Marín Rodríguez, R. Lack of kdr mutations in a population of Asian tiger mosquitoes from Costa Rica. Bull. Insectol. 2015, 68, 61-63.

22. Valderrama, A.; Chaves, L.; Futami, K. Evaluación de mutaciones kdr en Aedes albopictus (Skuse) en Panamá (Datos preliminares). Revista Médica de Panamá 2016, 36, 30-32.

23. Knipling, E.F. The Basic Principles of Insect Population Suppression and Management; U.S. Department of Agriculture: Washington, DC, USA, 1979.

24. Weidhaas, D.E.; Schmidt, C.H.; Seabrook, E.L. Field studies on the release of sterile males for the control of Anopheles quadrimaculatus. Mosq. News 1962, 22, 283-291.

25. Patterson, R.S.; Sharma, V.P.; Singh, K.R.P.; LaBrecque, G.C.; Seetharam, P.L.; Grover, K.K. Use of radiosterilized males to control indigenous populations of Culex pipiens quinquefasciatus Say: Laboratory and field studies. Mosq. News 1975, 35, 1-7. 
26. Patterson, R.S.; Lowe, R.E.; Smittle, B.J.; Dame, D.A.; Boston, M.D.; Cameron, A.L. Release of radiosterilized males to control Culex pipiens quinquefasciatus (Diptera: Culicidae). J. Med. Entomol. 1977, 14, $299-304$. [CrossRef]

27. Pal, R.; LaChance, L.E. The operational feasibility of genetic methods for control of insects of medical and veterinary importance. Annu. Rev. Entomol. 1974, 19, 269-291. [CrossRef]

28. Lorimer, N.; Lounibos, L.P.; Petersen, J.L. Field trials with a translocation homozygote in Aedes aegypti for population replacement. J. Econ. Entomol. 1976, 69, 405-409. [CrossRef]

29. Harris, A.F.; Nimmo, D.; McKemey, A.R.; Kelly, N.; Scaife, S.; Donnelly, C.A.; Beech, C.; Petrie, W.D.; Alphey, L. Field performance of engineered male mosquitoes. Nat. Biotechnol. 2011, 29, 1034-1037. [CrossRef]

30. Pan American Health Organization (PAHO). Technical Note on Transgenic Mosquitoes Engineered for Aedes Aegypti Control; PAHO: Washington, DC, USA, 2014.

31. Bellini, R.; Calvitti, M.; Medici, A.; Carrieri, M.; Celli, G.; Maini, S. Use of the sterile insect technique against Aedes albopictus in Italy: First results of a pilot trial. In Area-Wide Control of Insect Pests: From Research to Field Implementation; Vreysen, M.J.B., Robinson, A.S., Hendrichs, J., Eds.; Springer: Dordrecht, The Netherlands, 2007; pp. 505-515.

32. Knipling, E.F.; Laven, H.; Craig, G.B.; Pal, R.; Kitzmiller, J.B.; Smith, C.N.; Brown, A.W. Genetic control of insects of public health importance. Bull. World Health Organ. 1968, 38, 421-438.

33. World Mosquito Program. 'Eliminate Dengue' Program in Brazil. Available online: www.eliminatedengue. com.br (accessed on 17 March 2019).

34. Bourtzis, K.; Dobson, S.L.; Xi, Z.; Rasgon, J.L.; Calvitti, M.; Moreira, L.A.; Bossin, H.C.; Moretti, R.; Baton, L.A.; Hughes, G.L.; et al. Harnessing mosquito-Wolbachia symbiosis for vector and disease control. Acta Trop. 2013, 132, S150-S163. [CrossRef]

35. De Barro, P.J.; Murphy, B.; Jansen, C.C.; Murray, J. The proposed release of the yellow fever mosquito, Aedes aegypti containing a naturally occurring strain of Wolbachia pipientis, a question of regulatory responsibility. J. Verbraucherschutz Leb. 2011, 6, 33-40. [CrossRef]

36. Dutra, H.L.C.; dos Santos, L.M.B.; Caragata, E.P.; Silva, J.B.L.; Villela, D.A.M.; Maciel-de-Freitas, R.; Moreira, L.A. From lab to field: The influence of urban landscapes on the invasive potential of Wolbachia in Brazilian Aedes aegypti Mosquitoes. PLoS Negl. Trop. Dis. 2015, 9, e0003689. [CrossRef]

37. Lima, K.F.A. Avaliação Biológica de Machos Esterilizados por Radiação Gama, Para Utilização em Programas de Controle Populacional de Aedes Aegypti (Diptera: Culicidae). Ph.D. Thesis, Fundação Oswaldo Cruz, Recife, Brazil, 2015.

38. Lemos, S.G. Potencial do uso de Machos Esterilizados por Radiação Gama (60Co) Para o Controle Populacional de Aedes Aegypti (Diptera-culicidae): Um Caminho Biotecnológico do Laboratório Para o Campo. Ph.D. Thesis, Universidade Federal de Pernambuco, Recife, Brasil, 2017.

39. R Development Core Team. R: A Language and Environment for Statistical Computing; R Foundation for Statistical Computing: Vienna, Austria, 2013.

40. Arthur, V.; Gava, M.A. Controle do Aedes; Pesquisa Gazeta de Piracicaba: Piracicaba, Brasil, 2012.

41. Balestrino, F.; Medici, A.; Candini, G.; Carrieri, M.; Maccagnani, B.; Calvitti, M.; Maini, S.; Bellini, R. Gamma ray dosimetry and mating capacity studies in the laboratory on Aedes albopictus males. J. Med. Entomol. 2010, 47, 581-591. [CrossRef] [PubMed]

42. Oliva, C.; Jacquet, M.; Gilles, J.; Lemperiere, G.; Maquart, P.; Quilici, S.; Schooneman, F.; Vreysen, M.J.; Boyer, S. The sterile insect technique for controlling populations of Aedes albopictus (Diptera: Culicidae) on Reunion Island: Mating vigor of sterilized males. PLoS ONE 2012, 7, e49414. [CrossRef] [PubMed]

43. Bellini, R.; Balestrino, F.; Medici, A.; Gentile, G.; Veronesi, R.; Carrieri, M. Mating competitiveness of Aedes albopictus radio-sterilized males in large enclosures exposed to natural conditions. J. Med. Entomol. 2013, 50, 94-102. [CrossRef] [PubMed]

44. Lee, S.J. Development of eggs, larvae and pupae of Aedes albopictus (Skuse) (Diptera: Culicidae). Chin. J. Entomol. Zhanghua Kunchong 1994, 14, 13-32.

45. Weidhaas, C.H.; Schmidt, D.E. Mating ability of male mosquitoes, Aedes aegypti (L.) sterilized chemically or by gamma radiation. Mosq. News 1963, 23, 32-34.

46. Hallinan, E.; Rai, K.S. Radiation sterilization of Aedes aegypti in nitrogen and implications for sterile male technique. Nature 1973, 244, 9-368. [CrossRef] 
47. Economopoulos, A.P. Sexual competitiveness of gamma-ray sterilized males of Dacus oleae. Mating frequency of artificially reared and wild females. Environ. Entomol. 1972, 1, 490-497. [CrossRef]

48. Helinski, M.E.H.; Knols, B.G.J. Mating competitiveness of male Anopheles arabiensis mosquitoes irradiated with a semi- or fully-sterilizing dose in small and large laboratory cages. J. Med. Entomol. 2008, 45, 698-705. [CrossRef]

49. Helinski, M.; Parker, A.; Knols, B. Radiation induced sterility for pupal and adult stages of the malaria mosquito Anopheles arabiensis. Malar. J. 2006, 15, 5-41.

50. Abdel-Malek, A.A.; Tantawy, A.O.; Wakid, A.M. Studies on the eradication of Anopheles pharoensis Theobald by the sterile male technique using cobalt-60. I. Biological effect of gamma radiation on different developmental stages. J. Econ. Entomol. 1966, 59, 672-678. [CrossRef]

51. Proverbs, M.D. Induced sterilization and control of insects. Annu. Rev. Entomol. 1969, 14, 81-102. [CrossRef] [PubMed]

52. Yamada, H.; Vreysen, M.J.; Gilles, J.R.; Munhenga, G.; Damiens, D.D. The effects of genetic manipulation, dieldrin treatment and irradiation on the mating competitiveness of male Anopheles arabiensis in field cages. Malar. J. 2014, 13, 318. [CrossRef] [PubMed]

53. Feinendegen, L.E. Evidence for beneficial low level radiation effects and radiation hormesis. Br. J. Radiol. 2005, 78, 3-7. [CrossRef] [PubMed]

(C) 2019 by the authors. Licensee MDPI, Basel, Switzerland. This article is an open access article distributed under the terms and conditions of the Creative Commons Attribution (CC BY) license (http:/ / creativecommons.org/licenses/by/4.0/). 